\title{
Odd numbers: food banks and liposuction
}

Indicators of either impoverished or lavish lifestyles invariably come under immediate assault as being entirely in- valid or little more than sheer mathematical trickery. In the interest of avoiding such a tedious debate, what follows (Box I) are not indicators but, rather, just a few odd numbers, compiled by Wayne Kondro, CMAJ

\section{Box 1: The balance sheet}

\section{Canadians and poverty}

- Percentage of Canadians living below StatsCan's low-income cut-off line (defined as a family that spends more than $63 \%$ of its gross income on food, shelter and clothing): $15.5 \%$

Percentage of Canadians falling under the poverty line using the Organisation for Economic Co-operation and Development definition, i.e., those making less than half the nation's median after-tax income: $10.3 \%$ (sources: StatsCan and OECD)

- Annual welfare incomes by category and province (from high to low) in 2005:

- Single employable: \$8198 (Newfoundland) to \$3427 (New Brunswick)

- Disabled person: \$12 057 (Ontario) to $\$ 7851$ (Alberta)

- Single parent, 1 child: \$16 181 (Newfoundland) to \$12 326 (Alberta)

- Couple, 2 children: \$21 213 (PEI) to \$17 567

(New Brunswick)

(Source: National Council of Welfare)

- Jurisdiction with the lowest minimum wage: Newfoundland, $\$ 7$ per hour

- The highest: Nunavut, $\$ 8.50$

- Number of jurisdictions with a minimum wage over $\$ 8$ per hour: 3

- Number lower than $\$ 8$ per hour: 5

(Source: provincial labour ministries)

- Number of people who used a food bank in March 2006: 753458

- Percentage of food bank clients who are children: $41 \%$ (268 774 kids)

- Percentage who are pensioners: $6 \%$

- Percentage on disability income: $11 \%$

- Percentage who are employed: $13.4 \%$

Province with the highest per capita food bank use: Newfoundland, 5.6\%

- Next in line: Manitoba, 3.78\%; Ontario, 2.64\%, Saskatchewan 2.57\%

Number of food banks in Canada: 649

- Percentage of food banks that limit frequency of use to once per month: $62.4 \%$

(Source: Canadian Association of Food Banks)

- Federal government estimate of the number of homeless people: 150000

Non-governmental estimates: 200000 to 300000

- Average income, Aboriginal population, 2000: \$14 157

Average income, Canadian population: $\$ 30062$

(Source: Statistics Canada)

- Percentage of Aboriginal communities in Canada that must boil their water: 12 (roughly 100 communities)

- Number of houses on reserves without sewage services: 5486 of 88485

Percentage without hot running water: 3.7

Percentage without cold running water: 3.5

Percentage without flushing toilets: 3.5

(Source: Assembly of First Nations)

\section{Canadians and luxury}

- Estimated amount spent on cosmetic and plastic surgery in Canada in 2003: \$665 million (Source: Medicard, Canada's Patient Financing Company). More current numbers are unavailable, says Karyn Wagner, executive-director of the Canadian Society of Plastic Surgeons. "We can't afford to collect that kind of data."

- Credit Medical Corporation's estimated cost of cosmetic and plastic surgical procedures:

- Breast implant: $\$ 5000-\$ 6000$ (saline); $\$ 7000-\$ 8000$ (cohesive gel)

- Facelift: $\$ 10000$

- Browlift: $\$ 6000$

- Liposuction: \$2500 for first area, $\$ 1500$ for each additional area

- Annual membership dues for the Luxury Institute, which advises the chic on the best buys: US\$995

- Annual cost of Toronto Maple Leafs season tickets: \$1665$\$ 15750$

- Cost of renting 1 of 6 “Gondola Hospitality Suites" for a single Maple Leafs game: \$9061-\$10 861 .

- Cost of renting such a box at a Toronto Raptors game: "as low as \$1900."

- Daily summer rate at Vancouver Island's Aerie Resort "Villa Cielo," where the offerings include a king-size bed, double walk-in shower, yoga classes, organic meals and mushroomforaging expeditions led by a Benedictine monk: $\$ 625$

- Average home price in Canada: \$311 495 (Source: Canadian Real Estate Association)

Most expensive home now on the market: the 14-acre Edgemere Estate in Oakville, which is listed at $\$ 45$ million for 9 bedrooms, 17 bathrooms, sauna and therapy rooms, 21-seat theatre and private pebble beach

- Typical online dealer price of a stainless steel Rolex Oyster Perpetual Cosmograph Daytona watch, for which waiting lists of up to 7 years have been reported: $\$ 15000$

- Mercedes-Benz Canada vehicle sales in 2006: 14544

- BMW Group Canada vehicle sales in 2006: 23430

- Number of private aircraft registered in Canada as of Dec. 31, 2006: 31 018. Number of single engine aircraft registered: 24 314. (Source: Transport Canada)

- Cheapest of 163 Prada handbags listed in the Fall/Winter Styledrops 2007/2008 catalogue: US\$223 (most expensive: \$3059)

- Online cost of a single Bolivar Gold Medal cigar manufactured at the Partagas factory in Cuba: \$25.60 (box of 10 : $\$ 230.40$ )

- Going rate for 1 ounce of Almas Golden Caviar, which is culled from either albino sturgeon or those of an Oscietre sturgeon over 60 years of age: $\$ 700$

- List price, Park Avenue Liquor in New York, 1 bottle Macallan Lalique 50 -yr-old 92 single malt scotch whisky: $\$ 10000$ 